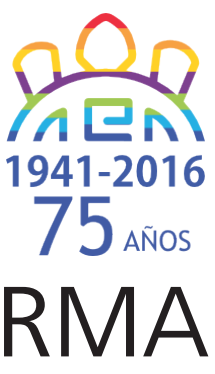

Arqueología

\section{De usos y recursos. Análisis funcional y de sustancias grasas mediante cromatografía gaseosas sobre artefactos líticos tallados}

\author{
Use-wear and fatty acids analyses of flaked lithic tools
}

\begin{abstract}
Resumen
En este trabajo se exploran las posibilidades y limitaciones que ofrece el uso integrado del estudio de sustancias grasas mediante cromatografía gaseosa y del análisis funcional de base microscópica sobre artefactos líticos tallados. La aplicación conjunta de estas metodologías busca obtener información acerca de los recursos orgánicos procesados con estos artefactos. Se presentan ejemplos experimentales y se toma como caso arqueológico una muestra de artefactos del sitio Cueva Zoro (Pdo. Lobería, Buenos Aires). Los resultados obtenidos indican la importancia de complementar estas dos vías analíticas independientes, que son especialmente útiles para el estudio de contextos con escasa preservación de materiales perecederos.
\end{abstract}

Palabras clave: ácidos grasos; análisis funcional; artefactos líticos tallados; Región pampeana; Pleistoceno final/ Holoceno temprano.

\begin{abstract}
The study of lipids through gas chromatography and the microscopic functional analysis on experimental lithic flaked artifacts and archaeological artifacts from Cueva Zoro site (Lobería, Buenos Aires) are presented. The possibilities and limitations of the combined approach of these methods are evaluated in order to obtain accurate information about organic resources. The results presented in this paper point toward the importance of complementing these two independent techniques and their significance for contexts lacking organic remains preservation.
\end{abstract}

Keywords: fatty acid analysis; use wear analysis; lithic; flaked artefacts; Pampean region; late Pleistocene/early Holocene.

Frecuentemente, no encontramos a simple vista en el registro arqueológico aquella información que nos falta. Resulta fundamental buscar alternativas que permitan ahondar en el estudio de los materiales disponibles, por ejemplo, mediante el uso de herramientas y métodos de otras disciplinas. En esta oportunidad, combinamos las posibilidades que nos brindan la química orgánica y la microscopía con el fin de acercarnos a los usos dados a diferentes materiales líticos y a los recursos procesados. Esta propuesta es especialmente importante para el estudio de contextos arqueológicos, como los hallados en el sector centro oriental de Tandilia (provincia de Bs. As.), donde la preservación de restos orgánicos es escasa o nula y los materiales recuperados son predominantemente líticos (Flegenheimer 2004; Mazzia y Flegenheimer 2012). No obstante, puede ser útil y extensible a otras investigaciones, al permitir crear un panorama cada vez más amplio sobre los recursos orgánicos utilizados y las actividades realizadas por los cazadores recolectores pampeanos.

En este marco, los objetivos del trabajo son explorar opciones para extraer la mayor cantidad de información posible de los conjuntos líticos aplicando dos metodologías independientes y combinadas; y a su vez, evaluar cómo se complementan, sus alcances y limitaciones. En esta ocasión, integramos el análisis funcional de base microscópica y el análisis de sustancias grasas mediante cromatografía gaseosa, dos vías analíticas que, en conjunto, permiten hacer inferencias acerca de los recursos aprovechados en el pasado y de la manera en que fueron utilizados, así como de las actividades relacionadas con ellos. 


\section{Materiales}

El conjunto lítico experimental está conformado por seis lascas de ortocuarcita del Grupo Sierras Bayas (OGSB). Cinco piezas fueron utilizadas en el procesamiento de distintos recursos, mientras que una lasca fue considerada muestra control para evaluar la posibilidad de contaminación de los materiales por manipulación. A partir del análisis de sustancias grasas y de rastros de uso buscamos, por un lado, evaluar la conservación e identificación de ácidos grasos sobre piezas líticas de diferentes tamaños y por otro lado, obtener una base de referencia que permita comparar los alcances y limitaciones del cruce de metodologías.

La Tabla 1 detalla las características de la experimentación. Los recursos utilizados incluyeron especies modernas de fácil acceso dado que el objetivo del análisis cromatográfico, en esta oportunidad, era solamente discriminar fuentes vegetales y animales en general y posibles mezclas. El mástic del enmangue de la punta de flecha Eg1 fue preparado con resina de pino calentada (Pinus pinaster y Pinus radiata) mezclada con ceniza tamizada. La pieza permaneció enmangada durante 26 semanas y luego de extraerla del enmangue fue almacenada en una bolsa plástica. La raedera Eg5 fue usada en la preparación de un arco experimental raspando (Figura 1C) madera de sauce ${ }^{1}$ (Salix sp.). Esta pieza permaneció depositada en bolsa plástica durante dos años antes de su análisis. Tres lascas fueron utilizadas con distintos recursos: una para corte de carne, otra para corte de vegetales y la última con mezcla de carne y vegetales; en los dos casos en que se utilizó carne se trató de carne vacuna y los vegetales procesados incluyeron hojas de gramíneas, frutos carnosos, tubérculos, raíces y bulbos (Figura 1). Luego de ser utilizadas, estas tres lascas fueron lavadas con agua y depositadas en bolsas plásticas hasta el momento de ser analizadas.

La lasca Eg6 es una muestra control realizada para considerar los ácidos grasos presentes en la roca sin uso, expuesta a condiciones ambientales y a nuestra manipulación. Dado que los lípidos de nuestra piel podrían transferirse a las superficies de los artefactos, puede permanecer la duda de si los mismos llegan a interferir en los resultados de los análisis cromatográficos (Evershed et al. 1992). Eg6 no fue utilizada y fue manipulada sin guantes por 18 hs durante las tareas de laboratorio, por lo que fue analizada directamente luego de su manipulación, sin mediar embalaje o depósito.

La muestra arqueológica incluye 13 artefactos líticos de diferentes tamaños y materias primas (Tabla 2) seleccionados al azar dentro de un conjunto de 48 piezas correspondientes a ocupaciones breves o de grupos reducidos en el sitio Cueva Zoro (Lobería, Buenos Aires)

\footnotetext{
${ }^{1}$ La elaboración del mástic, el enmangue y la preparación del arco tuvieron lugar durante el XI Curso de Talla y Tecnología Lítica dictado por Flegenheimer, Escola y Bayón, Necochea, 2007.
}

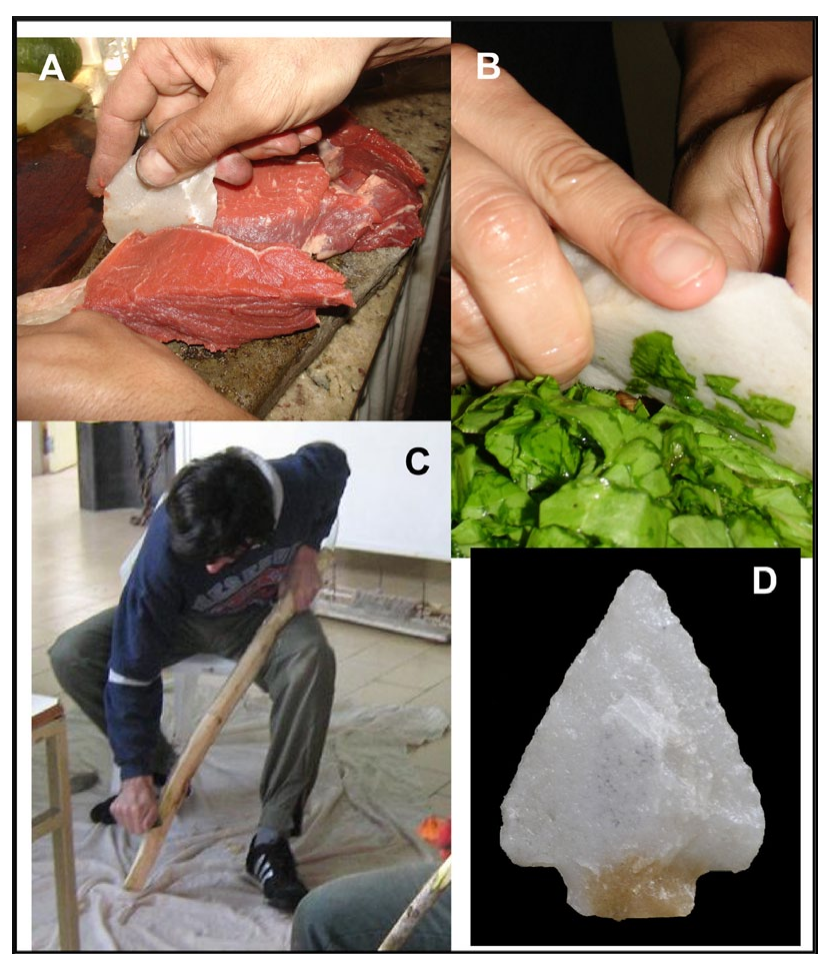

Figura 1. Tareas y piezas experimentales. A: corte de carne; B: corte de vegetales; C: raspado de madera para confeccionar un arco; D: punta de flecha.

Figure 1. Experimental tasks and tools. A: cutting meat. B: cutting vegetables; $C$ : wood scraping manufacturing a bow; $D$ : arrow point.

durante la transición Pleistoceno/Holoceno (Mazzia 2013). El sitio es un abrigo rocoso de dimensiones medianas (11 $\mathrm{m}$ de largo en su boca, una profundidad máxima hasta la pared del fondo es de 3,5 $\mathrm{m}$ y 1,5 $\mathrm{m}$ de altura máxima), ubicado en el extremo norte de Sierra Larga a unos 400 msnm, próximo a la cima (Figura 2). Se incluye en una microrregión localizada en el sector centro-este de Tandilia donde se relaciona espacial y materialmente con otros seis lugares arqueológicos (sensu Mazzia 2013b) que fueron visitados y/o habitados desde finales del Pleistoceno: Cerro La China 1, 2 y 3 (Flegenheimer 2004), Cerro El Sombrero Cima y Abrigo 1 (Flegenheimer 2003) y Los Helechos (Flegenheimer y Bayón 2000). Dos fechados radiocarbónicos ubican la ocupación efímera de Cueva Zoro entre 12.060 y 11.400 años AP (Mazzia 2013). En el conjunto lítico se destaca el uso de una importante diversidad de materias primas incluyendo OGSB y Fm. Balcarce (OFB), frecuentes en los sitios del área, cuarzo translúcido, metacuarcita, una roca silícea de matriz sedimentaria y una roca indeterminada con óxido de hierro. Estos materiales estaban contenidos en un paleosuelo, un sedimento limo-arenoso modificado por el desarrollo de un perfil de suelo enterrado (Mazzia 2013). Una muestra de este sedimento fue también analizada mediante cromatografía gaseosa (Tabla 2). Dado que los lípidos son parte constitutiva del medioambiente, sería posible que aquellos que pudieron ser absorbidos a partir del sedimento sean erróneamente interpretados como evidencias de recursos orgánicos en contacto con los artefactos arqueológicos (Buonasera 2007). En este caso, se registraron únicamente cuatro ácidos grasos en 
cantidades pequeñas. Por ello, se considera una absorción post-enterramiento mínima de sustancias provenientes de los sedimentos.

La aplicación de metodologías tendientes a conocer el empleo de recursos orgánicos resulta fundamental en sitios como Cueva Zoro y otros de la microrregión serrana dada la escasa preservación de macro-restos vegetales y animales que se presenta en los contextos.

\section{Métodos}

El análisis de sustancias grasas aplicado a objetos líticos tallados brinda la posibilidad de aproximarnos a los recursos orgánicos que fueron procesados con los mismos. Al analizar los materiales arqueológicos obtenemos una pequeña muestra de grasa que ha quedado atrapada durante su uso en las porosidades y micro fracturas de las rocas, tanto en los filos como en la superficie de las piezas.

Los lípidos, presentes en los tejidos de animales y vegetales, son un conjunto de moléculas orgánicas compuestas por átomos de carbono, hidrógeno y oxígeno. Son hidrofóbicas, presentan una importante estabilidad frente a altas temperaturas y una descomposición mínima a lo largo del tiempo en condiciones ambientales constantes (Evershed 1993; Feiser y Feiser 1960; Gunstone et al. 2007). Estas particularidades hacen factible el análisis de sustancias grasas en el marco de investigaciones arqueológicas.

Los ácidos grasos forman parte de este conjunto de biomoléculas. Se trata de compuestos naturales de cadena lineal y con número par de carbonos en cada molécula (Fankhauser 1994; Feiser y Feiser 1960; Rottländer 1990), de acuerdo con la longitud y el grado de insaturación de la cadena de carbonos pueden clasificarse en ácidos grasos de cadena corta (4 a 6), media (8 a 12), larga (14 a 20) y muy larga (más de 22), según la cantidad de átomos de carbono. En tanto que se diferencian en ácidos grasos saturados (sin dobles enlaces en su estructura molecular), monoinsaturados (con un doble enlace) y poli insaturados (con dos o más), de acuerdo con las insaturaciones presentes en la cadena (Bondia Pons 2007; Feiser y Feiser 1960; IUPAC 1997). Ambas características influyen en su persistencia en las piezas arqueológicas: la inestabilidad y la probabilidad de degradación de los ácidos grasos aumentan cuanto mayor es el número de átomos de carbono en la cadena y cuanto mayor es el número de insaturaciones que presenta (Malainey et al.1999).

La cromatografía de gases es una técnica analítica utilizada para la separación, identificación y cuantificación de lípidos. Los análisis presentados en este trabajo fueron realizados en dos laboratorios diferentes pero con equipamientos similares y enmarcados por los mismos protocolos de extracción y procesamiento de las muestras (descriptos detalladamente en Mazzia 2010-2011).

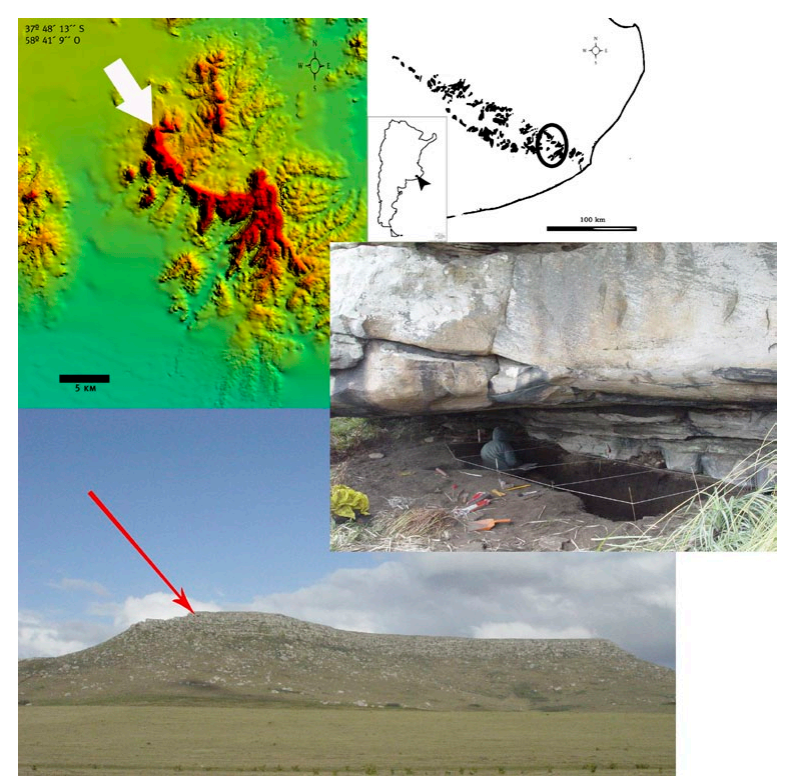

Figura 2. Ubicación del sitio Cueva Zoro, centro-este de Tandilia, provincia de Buenos Aires

Figure 2. Location of Cueva Zoro site, central-east portion of the Tandilia range, Buenos Aires province

El análisis de los materiales de Cueva Zoro y la lasca experimental manipulada fue realizado en colaboración con la Dra. Constela (Plapiqui-UNS-CONICET, Bahía Blanca) $)^{2}$. Las cinco piezas experimentales restantes fueron analizadas junto a la Ing. Sánchez en el laboratorio de la empresa Materia Hnos. Oleochemicals ${ }^{3}$ (Mar del Plata). En ambos casos, previamente al trabajo en laboratorio, las piezas solamente fueron lavadas con agua para remover el sedimento. Dado que los artefactos analizados medían entre 2 y $10 \mathrm{~cm}$, las expectativas de obtener la cantidad de grasa necesaria en el muestreo eran limitadas, por ello, para la extracción de las sustancias fueron sumergidos completamente en solvente, permaneciendo en vasos de precipitación tapados, durante 24 hs con agitación intermitente. Esta condición de extracción trae aparejado que los resultados obtenidos no provengan solamente de los filos sino de la pieza en su totalidad, pudiendo incluir una mezcla de las sustancias atrapadas a partir del uso de los diferentes filos. A continuación los extractos fueron sometidos a un protocolo de metilación que implica la preparación de ésteres metílicos, derivados de las muestras de lípidos, susceptibles de ser analizados mediante cromatografía (Cert et al., 2000).

Los resultados se obtuvieron en forma de cromatogramas. A partir de ellos se determinó el porcentaje en peso de

\footnotetext{
2 En Plapiqui-UNS-CONICET se utilizó un cromatógrafo gaseoso HP 4890 con un detector de ionización de llama FID. Para el análisis de las muestras se trabajó con una columna capilar SP -2560 de 100 m de longitud, 0,25 $\mathrm{mm}$ de diámetro interno y 0,2 $\mathrm{mm}$ de espesor del film. La temperatura del inyector fue de $175^{\circ} \mathrm{C}$, el volumen de inyección de $1 \mathrm{ml}$ y la temperatura del detector de $260^{\circ} \mathrm{C}$.

${ }^{3}$ En Materia Hnos. Oleochemicals se usó un cromatógrafo gaseoso HP 6890N con un detector de ionización de llama FID y un inyector Back automático. Se utilizó una columna capilar Supelcowax 10. La temperatura de la columna fue de $200^{\circ} \mathrm{C}$, la del inyector $250^{\circ} \mathrm{C}$ y la del detector $280^{\circ} \mathrm{C}$.
} 
cada ácido graso en relación con el total existente en la muestra, comparándolo posteriormente con bases de datos de referencia arqueológicas y experimentales (por ejemplo: Babot et al. 2007; Buonasera 2007; Frére et al. 2010; Mazzia 2010-2011; Patrick et al. 1985; Rottländer 1990) y de recursos actuales (Abd El-Baky et al. 2004; Anónimo1993; Brenner y Bernasconi 1997; Cañabate Guerrero y Sánchez Vizcaíno 1995; Fankhauser 1994; Fezler 1995; Malainey et al. 1999; Muhamad y Mohamad 2012; Pond et al. 1997; Robinson et al. 1991; Sengör et al. 2003; U.S. Testing Company S/F, entre otros).

El análisis funcional de base microscópica se realizó luego de la extracción de las muestras de grasa ya que la limpieza con detergente y alcohol que requieren las piezas para su observación eliminaría los residuos grasos. Este tipo de análisis permite el acercamiento a variados aspectos de las sociedades humanas pasadas respecto al uso y aprovechamiento de los objetos, a los otros recursos orgánicos asociados a estas tecnologías líticas y a las diferentes actividades desarrolladas.

La metodología se basa en la caracterización y reconocimiento de rastros microscópicos que se desarrollan en los filos de los instrumentos durante su uso, permitiendo inferir tareas realizadas, materiales trabajados, intensidad de uso y alteraciones postdepositacionales y estado de conservación de dichos rastros (Anderson-Gerfaud1981; Castro 1994; Keeley 1980; Leipus y Mansur 2007; Mansur-Franchomme 1983, 1999; Semenov 1964, entre otros).

El análisis comprende el barrido completo de las superficies y filos y el registro de variables referidas a cuatro clases de rastros: esquirlamiento y/o redondeamiento de los filos, estrías, micropulidos y residuos microscópicos (Mansur 1999). La caracterización funcional de las piezas se realizó en base a las categorías propuestas por Mansur y Lasa (2005) en: 1) uso seguro, 2) uso probable, 3) no utilizadas, 4) no determinables. Se empleó un equipo óptico integrado por una lupa binocular (Leica S6D) y un microscopio metalográfico (Olympus BH2-UMA), con sistema directo para captura y digitalización de imágenes. Los aumentos utilizados variaron entre los $5 x$ a los 50x en el caso de la lupa y desde los 50x hasta 500x para el microscopio. Los pasos metodológicos seguidos fueron: análisis en lupa binocular y microscopía óptica de reflexión; localización de rastros de uso, accidentes y alteraciones; captura y tratamiento de imágenes (según Vila y Gallart 1993); determinación funcional (Leipus 2006; Mansur-Franchomme 1986-1990, 1999).

Ambos análisis tienen antecedentes de cruces metodológicos, aunque con aplicación muy desigual sobre artefactos líticos. El análisis funcional es el que más frecuentemente se combinó con otras metodologías orientadas a la identificación de recursos, combinándose con el estudio de residuos, principalmente fibras animales y vegetales (fitolitos, almidones, colágeno, cabellos y proteínas). Prácticamente desde sus comienzos, el análisis funcional fue aplicado sobre artefactos tallados en conjunto con análisis de residuos adheridos mediante distintas técnicas (por ejemplo, Microscopio Electrónico de Barrido, Dispersión de Rayos X, Contra-inmunoelectroforesis, Espectrometría infrarroja transformada de Fourier o lupas estereoscópicas) evaluando las ventajas y limitaciones de ambos métodos y de su uso combinado (por ejemplo, Álvarez 2000-2002; Anderson 1980, Borel et al. 2014; Cesaro y Lemorini 2012; Hardy et al. 2001; Pawlik 2004; Portillo et al. 2013; Rots y Williamson 2004). Estas investigaciones destacan la utilidad de la combinación metodológica en la identificación de los mecanismos de formación de micropulidos y la posibilidad de reconocer el tipo de recurso procesado, la actividad realizada, la obtención de información paleoambiental y la determinación de pulidos atípicos o ambiguos (Álvarez 2000-2002; Anderson 1980; Borel et al. 2014; Cesaro y Lemorini 2012; Hardy y Garufi 1998; Mansur-Franchomme 1983; Pedergnana y Blasco 2015; Robertson y Attenbrow 2008). También son utilizadas en conjunto con el fin de identificar prácticas de enmangue y como parte de una creciente discusión en torno al origen de la planificación, la conducta compleja y las tecnologías de caza (Langejans y Lombard 2015; Lombard 2005; Lombard y Phillipson 2010; Pawlik 2004; Rots 2010, 2014; Rots y Williamson 2004).

Otras estudios combinan el análisis funcional con tipos específicos de residuos como microfósiles vegetales -fitolitos o almidones- en artefactos de molienda (Fullagar et al. 2015; Liu et al. 2010; Portillo et al. 2013) y en artefactos líticos tallados (Babot et al. 2013; Barton et al. 1998; Fullagar et al. 2012; Kealhofer et al. 1999; Perry 2002); o con el análisis de hemoglobina (Högberg et al. 2009; Sterner Miller et al. 2013). Estas últimas tres aproximaciones en conjunto forman parte de una propuesta metodológica evaluada en artefactos líticos tallados de Tierra del Fuego (Álvarez et al. 2009; Briz et al. 2014). Asimismo, estos cruces metodológicos son aplicados al estudio de problemáticas concretas como patrones de subsistencia, cambios culturales o la función de instrumentos específicos (Cooper y Nugent 2009; Hardy et al. 2001; Hardy y Moncel 2011; Kononenko 2007; Perry 2002; Robertson et al. 2009). Las conclusiones apuntan a la utilidad de la combinación metodológica para una comprensión más efectiva de las prácticas de subsistencia y del uso de los instrumentos, dado que permite alcanzar resultados que ninguna de las metodologías podría producir por sí misma (Hardy 2009; Högberg et al. 2009; Kononenko 2011; Portillo et al. 2013; Sterner Miller et al. 2013).

A diferencia del análisis funcional los estudios de sustancias grasas mediante cromatografía de gases estuvieron orientados principalmente al análisis de materiales cerámicos (por ejemplo: Bonomo et al. 2012; Cañabate Guerrero y Sánchez Vizcaíno 1995; Cordero y March 2013; Eerkens 2007; Gómez Otero et al. 2014; 
González de Bonaveri y Frère 2002, 2004; Illescas et al. 2012; Malainey et al. 1999; Pérez et al. 2013; Pérez Meroni et al. 2010; Stoessel et al. 2015, entre otros), instrumental de molienda (Babot 2004; Babot et al. 2007) y pigmentos minerales (por ejemplo: Di Prado et al. 2007; Fiore et al. 2008; Maier et al. 2007). Sólo recientemente ha comenzado a aplicarse al estudio de artefactos líticos tallados (Escola et al. 2013; Babot et al. 2013; Flegenheimer et al. 2015; Galanidou 2006; Mazzia 2010-2011, 2011, 2013; Mazzia y Flegenheimer 2015). Frente a la multiplicidad de cruces metodológicos entre el análisis funcional y otras metodologías, la combinación del análisis de sustancias grasas sobre instrumentos tallados con otros métodos es verdaderamente escasa e incluyen dos estudios recientes. Uno combina el análisis de ácidos grasos y de microfósiles sobre un conjunto de cuchillos/raederas de módulo grandísimo y sus desechos asociados, procedentes de Antofagasta de la Sierra, identificando la función especializada de estos instrumentos en las etapas iniciales del laboreo agrícola (Escola et al. 2013). El segundo es el único antecedente del cruce metodológico entre el análisis funcional y el de sustancias grasas junto al análisis de microfósiles para conocer la historia de vida de artefactos identificados como puntas de proyectil transformadas en cuchillos; los resultados cruzados de las tres metodologías permitieron comprobar esta transformación junto con modificaciones morfológicas y la naturaleza diversa de los recursos procesados (Babot et al. 2013).

En nuestra área de estudio, artefactos líticos de distintos sitios han sido estudiados mediante análisis funcionales (Flegenheimer y Leipus 2007, Leipus 2010) o de sustancias grasas (Flegenheimer et al. 2015; Mazzia 2011, 2013, Mazzia y Flegenheimer 2015), pero no fueron cruzados en los mismos conjuntos. Hasta el momento, en la microrregión serrana del centro-este de Tandilia sólo se han realizado en combinación análisis de sustancias grasas y de microfósiles por medio de microscopía óptica sobre materiales manufacturados por picado y pulido en un molino de mano correspondiente a ocupaciones del Holoceno tardío del sitio La China 1 (Babot et al. 2007) y una piedra discoidal decorada del contexto de ocupaciones de tempranas del sitio Cerro El Sombrero Cima (Flegenheimer et al. 2013).

\section{Interpretación e Integración de los Resultados}

Los pasos experimentales y sus resultados para ambos análisis se detallan en la Tabla 1. El uso de las piezas involucró un tiempo mínimo teniendo en cuenta que en las rocas heterogéneas, y en las cuarcitas en particular, la formación de micropulidos diagnósticos es lenta (Leipus 2006; Mansur-Franchomme 1983). Durante el procesamiento de carnes y vegetales se observó que el contacto con el material trabajado se produjo en toda la superficie del artefacto y no solo en el filo. Por ello, los residuos visibles que quedaban en los objetos provenían tanto del contacto directo con el recurso como de los restos presentes en las manos que realizaban el trabajo.

Todas las piezas experimentales brindaron muestra de grasa suficiente para ser analizada. A partir del análisis funcional se pudo determinar el uso seguro de una pieza, el uso probable de otras dos y dos piezas sin ninguna alteración. Los resultados de Eg6 son importantes para descartar la contaminación por manipulación con sustancias grasas presentes en nuestra piel (Evershed et al. 1992), ya que solamente se registraron cuatro ácidos grasos en proporciones muy pequeñas, lo que implica que la cantidad de grasa acumulada es despreciable.

La lasca Eg2 utilizada sobre carne y vegetales presenta rastros de uso probable al igual que Eg4, utilizada para el corte de vegetales, es decir, podemos considerar que las piezas se usaron, pero no identificar la tarea ni el material trabajado. Eg4 presenta proporciones importantes de ácidos grasos poli-insaturados de cadena larga/muy larga, y una relación entre las proporciones de los ácidos esteárico, oleico y linoleico comparable a las bases de referencia de recursos vegetales actuales (Rottländer 1990; U.S. Testing Company S/F). Eg2 exhibe una proporción demasiado alta de ácidos grasos no identificados (mayor al 46\%). Este dato resulta llamativo dado que en una muestra arqueológica en la que no se pueden identificar más del $30 \%$ de sus compuestos, no resulta posible determinar el origen del recurso orgánico. A esto debe sumarse el registro de ácidos grasos de cadena media, que en las muestras arqueológicas es interpretado como el producto de la degradación de ácidos grasos de cadena más larga (Buonasera 2007; Evershed 2008; Malainey et al. 1999). En este caso, estos datos son producto de la mezcla de recursos de diferentes orígenes (carne y vegetales). Resulta necesario ahondar en por qué el análisis de esta mezcla produce el resultado comúnmente interpretado como producto de la degradación de las sustancias grasas.

La lasca Eg3 fue utilizada para cortar carne y su determinación funcional es la de una pieza no utilizada, resultado consistente con las observaciones experimentales realizadas por diversos autores con respecto al grado y tiempo de desarrollo de los micropulidos en cuarcitas durante el procesamiento de materiales blandos (carne, piel fresca, vegetales no leñosos); que plantean que las tareas sobre estos materiales requieren un tiempo prolongado, entre 30 a 60 minutos para que se desarrollen micropulidos diagnósticos y en el caso del procesamiento de carne, el micropulido sólo alcanza un desarrollo indiferenciado independientemente del tiempo de uso (Gibaja et al. 2002; Leipus 2006; Keeley 1980; MansurFranchomme 1983; Tabla 1). El análisis cromatográfico mostró una relación entre los porcentajes de los ácidos palmítico, esteárico, oleico y linoleico característica de las grasas animales, principalmente por el predominio del ácido oleico por sobre las demás sustancias (Evershed et al. 2002; Malainey 2007; Regert 2011; Robinson et al. 1991). 


\begin{tabular}{|c|c|c|c|c|c|c|}
\hline Pieza & Recurso & Tarea & $\begin{array}{l}\text { Tiempo } \\
\text { de uso }\end{array}$ & $\begin{array}{l}\text { ANÁLISIS CROM ATOGRÁFICO } \\
\text { AG identificados* }\end{array}$ & $\begin{array}{l}\% \text { AG no } \\
\text { identificados }\end{array}$ & $\begin{array}{l}\text { ANÁLISIS } \\
\text { FUNCIONAL } \\
\text { Determinación } \\
\text { funcional }\end{array}$ \\
\hline $\begin{array}{l}\text { Eg } 6 \\
\text { Lasca } \\
\text { OGSB }\end{array}$ & $\begin{array}{l}\text { Secreciones } \\
\text { de la mano }\end{array}$ & $\begin{array}{l}\text { Manipula- } \\
\text { ción }\end{array}$ & $18 \mathrm{hs}$ & $\begin{array}{l}\text { Muestra de grasa muy } \\
\text { pequeña con: C14 }(12,95) \text {, } \\
\text { C16 }(65,38) \text {, C18 }(17,1), C 18: 2 \\
(4,57)\end{array}$ & - & No analizada \\
\hline $\begin{array}{l}\text { Eg2 } \\
\text { Lasca } \\
\text { OGSB }\end{array}$ & $\begin{array}{l}\text { Carne y } \\
\text { vegetales }\end{array}$ & corte & $48 \mathrm{~min}$ & $\begin{array}{l}\mathrm{C} 10(0,01), \mathrm{C} 11(0,76), \mathrm{C} 12 \\
(3,32), \mathrm{C} 13(29,43), \\
\mathrm{C} 14(14,65), \mathrm{C} 14: 1(1,08), \mathrm{C} 15 \\
(0,2), \mathrm{C} 16: 1(0,7), \mathrm{C} 18: 1(0,3), \\
\mathrm{C} 18: 2(0,8), \mathrm{C} 18: 3 \mathrm{n} 3(0,3), \\
\mathrm{C} 20(0,02), \mathrm{C} 20: 1(0,46), \\
\text { C20:2 }(0,34), \mathrm{C} 21: 1(1,12)\end{array}$ & 46,63 & Uso probable \\
\hline $\begin{array}{l}\mathrm{Eg} 4 \\
\text { Lasca } \\
\text { OGSB }\end{array}$ & Vegetales & corte & $45 \mathrm{~min}$ & $\begin{array}{l}\text { C14 (2,54), C14:1 }(0,22), C 15 \\
(0,86), C 16(13,18), C 16: 1 \\
(1,72), C 17(1,28), C 17: 1 \\
(0,36), C 18(23,47), C 18: 1 \\
(20,02), C 18: 2(6,26), C 18: 3 n 3 \\
(0,7), C 20(0,37), C 20: 2(9,35), \\
\text { C21:1 }(0,15), C 21: 2(9,45), \\
\text { C22:2 }(8,32)\end{array}$ & 0,67 & Uso probable \\
\hline $\begin{array}{l}\text { Eg3 } \\
\text { Lasca } \\
\text { OGSB }\end{array}$ & Carne & corte & $50 \mathrm{~min}$ & $\begin{array}{l}\text { C12 (0,08), C14 (3,67), C14:1 } \\
(0,74), C 15(1), C 16(23,94), \\
\text { C16:1 }(3,4), C 17(2,57), C 17: 1 \\
(1,14), C 18(19,42), C 18: 1 \\
(40,14), C 18: 2(2,76), C 18: 3 n 3 \\
(0,43), C 20(0,14)\end{array}$ & 0,25 & No utilizada \\
\hline $\begin{array}{l}\text { Eg1 } \\
\text { Punta } \\
\text { triangular } \\
\text { pequeña } \\
\text { OGSB }\end{array}$ & $\begin{array}{l}\text { Mástic/ } \\
\text { madera }\end{array}$ & Enmangue & 26 sem & $\begin{array}{l}\text { C14 (4,78), C15 (0,7), C16 } \\
(26,42), \text { C16:1 }(1,77), C 17 \\
(1,64), C 18(29,7), C 18: 1 \\
(27,73), C 18: 2(1,7), C 20: 2 \\
(5,53)\end{array}$ & - & No utilizada \\
\hline $\begin{array}{l}\text { Eg5 } \\
\text { Raedera } \\
\text { OGSB }\end{array}$ & Madera & Raspado & $40 \mathrm{~min}$ & $\begin{array}{l}\text { C16 (9.91), C16:1 (0,92), C17 } \\
(1,8), \text { C18 (33), C18:1 (29,3), } \\
\text { C18:2 (4,07), C20:2 (8,25), } \\
\text { C22:2 (11,2) }\end{array}$ & 0,99 & $\pi / M$ \\
\hline
\end{tabular}

*Entre paréntesis se expresan los porcentajes de cada ácido graso identificado en relación con el total de la muestra. Referencias: OGSB:

Ortocuarcita Grupo Sierras Bayas; $\mathrm{T}$ : trabajo transversal; M: madera.

Tabla 1. Características de la experimetación y resultados de los análisis de ácidos grasos y

funcional.

Table 1.Characteristics of the experiment and results from fatty acids and use-wear analyses.
La pieza Eg1 es una punta de flecha enmangada y utilizada durante un curso de talla para realizar unos pocos tiros inexpertos. Los resultados cromatográficos evidencian presencia de aceites vegetales, principalmente por la proporción en la que se presenta el ácido eicosadienoico (C20:2), sólo detectado en las muestras Eg1, 2, 4 y 5. Por el contrario, la punta no presenta rastros de uso microscópicos.

Finalmente, la raedera Eg5, utilizada en el raspado de madera para confeccionar un arco, es la única que presenta rastros de uso diagnósticos (Figura 3A). En tanto que en la muestra de grasa se destacan las proporciones en las que se registraron los ácidos eicosadienoico y docosadienoico (C20:2 y C22:2), ambos también presentes en la pieza utilizada para procesar vegetales (Eg4).

Las 13 piezas arqueológicas brindaron muestras de sustancias grasas que permitieron realizar determinaciones con diversos grados de especificidad (Tabla 2). Al descartarse la posibilidad de una contaminación significativa por aportes de sustancias presentes en la matriz sedimentaria, resulta posible sostener que estos artefactos estuvieron en contacto con recursos orgánicos en el pasado. Dado que los resultados, y la discusión sobre los mismos, ya fueron presentados en detalle (Mazzia 2013) se prestará mayor atención en esta oportunidad al cruce de los mismos con los datos provenientes del análisis de rastros de uso.

El análisis funcional permitió identificar el uso seguro de cuatro instrumentos y el uso probable de una lasca. Los ocho artefactos restantes presentaron alteraciones no determinables debido al escaso desarrollo de los micropulidos (Tabla 2). De los cuatro instrumentos con uso seguro, la raedera de filos convergentes Z4 57evidencia el uso de ambos filos sobre material vegetal duro, probablemente madera. Sobre el filo recto (Figura 3C, II) se identificó una cinemática de trabajo longitudinal, mientras que con el filo cóncavo (Figura 3C, I) se habría realizado trabajo transversal. El análisis cromatográfico evidencia mezcla de recursos orgánicos de origen vegetal y animal, en la que se incluirían lípidos de peces de agua dulce (Mazzia 2013). La interpretación de la presencia de aceites vegetales, basada principalmente en la preponderancia del ácido linoleico (C18:2) (Robinson et al. 1991; Rottländer 1990; U.S. TestingCompany S/F) se ve fortalecida por los resultados del análisis funcional. Dado que el procesamiento de recursos blandos como la carne, no desarrollan micropulidos diagnósticos en las ortocuarcitas, el uso de la raedera para el procesamiento de animales terrestres y acuáticos registrado a partir de las sustancias grasas no puede confirmarse ni descartarse mediante análisis microscópico.

El análisis funcional de Z1 59 permitió determinar su uso 
para trabajo transversal sobre piel con el filo retocado (Figura 3B, I). El registro lipídico se asemeja al anterior, con evidencias de un aporte vegetal en las sustancias debido a la preponderancia del ácido linoleico (C18:2) (Robinson et al. 1991; Rottländer 1990; U.S. Testing Company S/F). Los ácidos grasos de cadena larga/muy larga, insaturados y pertenecientes a las series n3 y n6, en las proporciones en las que fueron registrados, pueden ser relacionados con peces de agua dulce (Brenner y Bernasconi 1997; Costa Angrizani y Constenla 2010; Evershead et al. 1992; Robinson et al. 1991). A esto debe sumarse que los valores registrados para los ácidos C14:0, C16:0, C18:0, C18:1, C18:2, 18:3n3 y C20:4n6 se encuentran en proporciones similares a aquellas descriptas para la composición lipídica de carne cruda de guanaco (Frère et al. 2010). La integración de los resultados da cuenta del procesamiento de pieles, posiblemente de guanaco, además del posible contacto de esta pieza con recursos vegetales y animales de agua dulce. Ciertos autores (Högberg et al. 2009; Van Gijn 1986) sostienen que los micropulidos diagnósticos del procesamiento de pescado son difíciles de reconocer. Experimentos de procesamiento de peces con obsidianas muestran un desarrollo de micropulidos diagnósticos que requiere tiempos de uso prolongados, de más de 30 minutos (Hurcombe 1992; Kononenko 2011). Entonces en ortocuarcitas, con desarrollo mucho más lento que en rocas homogéneas (Mansur-Franchomme 1983, Leipus 2006) el tiempo de uso debe ser mucho más prolongado. Puede considerarse que el instrumento también haya sido usado en el procesamiento de peces en una tarea de corta duración.

El instrumento Z1 60, manufacturado sobre una roca silícea de matriz sedimentaria, posee dos filos de raedera, uno activo y otro agotado con evidencias de reactivación, y una punta burilante. Aunque la superficie del artefacto presenta un aspecto brilloso al microscopio, producto de una alteración post-depositacional leve, sobre dos de los filos fue posible determinar que fueron utilizados para trabajar madera, con distintas cinemáticas: el filo recto (Figura 3D, I) con movimiento longitudinal y el filo convexo (Figura 3D, II) evidencia movimientos transversales. Los resultados del análisis cromatográfico fueron interpretados como producto de mezcla de sustancias grasas de diferentes orígenes (Mazzia 2013). La relación entre los ácidos oleico y linoleico (C18:1 y C18:2), con una leve preponderancia del segundo llevan a considerar la presencia de aceites vegetales en la mezcla. Nuevamente, la integración de los resultados de ambos métodos apunta a considerar que este instrumento fue utilizado para el procesamiento de recursos vegetales durante períodos prolongados. A esto debe sumarse que, de acuerdo con el análisis tecno-morfológico, este instrumento compuesto tuvo un uso intensivo. Por lo tanto, al considerar su historia de vida resulta esperable encontrar entre las sustancias analizadas la mezcla de grasas de distinto origen producto de su utilización para el procesamiento de diferentes recursos orgánicos, incluyendo materiales blandos de origen animal que no habrían dejado rastros.

La última pieza con uso seguro en base al análisis microscópico es una lasca de OFB (Z1 34; Figura 4A), en la cual pudo identificarse cinemática transversal pero no el tipo de material trabajado. El registro lipídico es diverso y abundante, siendo llamativo si se tiene en cuenta que la calidad para la talla de estas cuarcitas que afloran en el mismo cerro en el que se encuentra el sitio es mayoritariamente mala o regular y su uso se asocia a un aprovechamiento expeditivo (Bayón et al. 2006; Valverde 2006). Los ácidos grasos identificados sugieren su uso para procesamiento de recursos animales acuáticos y vegetales (Mazzia 2013) en base, principalmente, a que la relación registrada entre los ácidos C18:0; C18:1; C18:2 es característica de aceites vegetales (Robinson et al. 1991; Rottländer 1990; U.S. Testing Company S/F). Asimismo, los ácidos grasos 20:4n6, C20:5n3, C22:1n9, C22:5n3 y $\mathrm{C} 22: 6 \mathrm{n} 3$, en proporciones similares, fueron identificados en las composiciones de peces de agua dulce. Entonces, los resultados de las distintas metodologías resultan en este caso parcialmente complementarios. Ambos indican el uso del artefacto: el análisis funcional informa sobre al menos una de las cinemáticas y los ácidos grasos acerca de los recursos procesados, aunque dado que la muestra de grasa fue extraída de la totalidad de la pieza, no es posible asociar la cinemática con alguno de los materiales trabajados. El escaso desarrollo de los rastros de uso

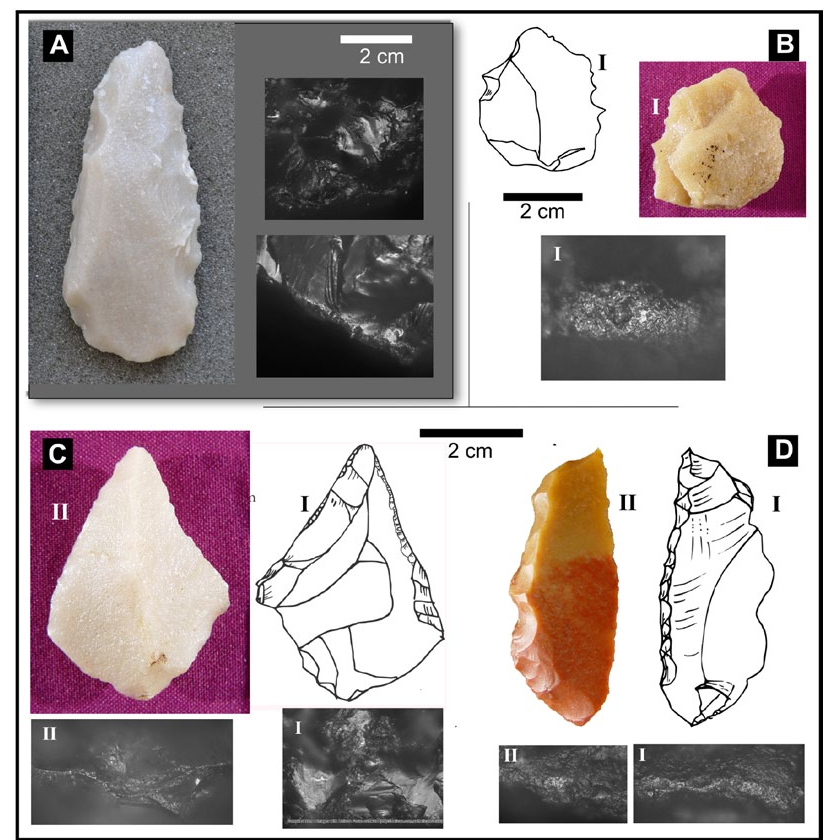

Figura 3. Instrumentos con micro-rastros de uso. A: Raedera experimental, raspado de madera. B: Z1 59; I: filo retocado con rastros de trabajo transversal sobre piel. C: Z4 57; I: raspado y II: corte, ambos sobre material vegetal duro. D: Z1 60; I: corte y II: raspado, ambos sobre madera.

Figure 3. Tools with diagnostic use-wear traces. A: experimental side-scraper, scraping wood wear traces. B: 21 59; I: retouched edge with use-wear traces from scraping hide. C: Z4 57; I: scraping and II: cutting hard plant material. D: Z1 60; I: cutting and II: scraping wood. 
puede deberse a un tiempo corto de uso de la pieza, al tiempo requerido para la formación de rastros sobre esta variedad de cuarcita o a la naturaleza de los materiales trabajados (vegetales blandos y/o peces).

En el caso de Z158 (Figura 4B), el análisis funcional registró micropulidos indiferenciados indicando el uso de la pieza pero sin determinación del material trabajado o la tarea realizada. Los resultados cromatográficos apuntan en igual dirección, interpretándose el uso de la pieza en actividades relacionadas con el procesamiento de recursos orgánicos indeterminados (Mazzia 2013), en base a la identificación de una relación C18:2/ C18:1 con primacía del primero, característica de los aceites vegetales (Robinson et al. 1991; Rottländer 1990; U.S. Testing Company S/F) pero en combinación con la presencia de más del 20\% de C16, registrada, por ejemplo, en carne cruda de coipo (Frère et al. 2010).

Las tres piezas restantes de OGSB, Z1 13, Z4 3 y Z1 24 (Figura 4D, E y C, respectivamente), evidencian nuevos alcances en la combinación de las metodologías usadas. Estas tres lascas presentan micropulidos indiferenciados y el uso de las piezas se sustenta por los análisis de sustancias grasas, aunque no se pudo determinar microscópicamente el material trabajado o la tarea realizada. En la muestra Z1 13 los registros resultan comparables con lípidos de origen vegetal pero con aportes de sustancias grasas animales. Puede sugerirse que esta pequeña lasca bipolar fue utilizada para procesar recursos orgánicos, sin poder determinarse un origen inequívoco de las sustancias (Mazzia 2013). Las muestras experimentales utilizadas sobre carne y vegetales presentaron micropulidos indiferenciados y también ausencia de alteraciones, con tiempos de uso de 48 min y 50 min respectivamente; mientras que la pieza experimental utilizada sobre madera con tiempos similares presentó rasgos diagnósticos (Tabla 1). En tal sentido, la lasca Z1 13 podría haberse utilizado tanto sobre carne cruda como sobre vegetales.

La muestra obtenida de Z4 3 evidencia su uso sobre recursos orgánicos indeterminados, resultado del registro de una alta proporción de ácidos grasos no identificados y de ácidos grasos saturados de cadena corta y media, identificados en muestras arqueológicas, posiblemente como resultado de la degradación de otros compuestos más inestables (González de Bonaveri y Frère 2002; Babot et al. 2007; Buonasera 2007). En este caso, ninguna de las metodologías usadas nos permiten aproximar el modo de uso o los recursos procesados. En la muestra Z1 24 se detectó una relación entre los ácidos esteárico, oleico y linoleico similar a la descripta típicamente para los aceites vegetales (Robinson et al. 1991; Rottländer 1990; U.S. Testing Company S/F). Integrando los resultados obtenidos, sólo podemos proponer que estas tres piezas fueron utilizadas para procesar recursos orgánicos incluso las pequeñas lascas- probablemente en tareas de corta duración.
Los cuatro artefactos restantes fueron confeccionados sobre diversas materias primas con escasa representación en el conjunto. No presentan rastros de uso diagnósticos, todos tienen alteraciones probables por uso aunque no determinables. En cuanto al análisis de sustancias grasas Z4 40 (Figura 4F) y Z1 50 (Figura 4H) (Tabla 2) comparten el registro de una relación entre los ácidos grasos palmítico, esteárico, oleico y linoleico que es el encontrado en las bases de referencia actual de grasas animales terrestres (Robinson et al. 1991; U.S. Testing Company S/F). De acuerdo con los valores, también bajos, de ácido linoleico presentes en las muestras experimentales Eg5 (madera) y Eg1 (mástic) no se descarta la posibilidad de la existencia de enmangue en estas piezas. Considerando las evidencias de ambas metodologías, es posible que estas lascas hayan sido utilizadas para el procesamiento de carne y que hayan estado enmangadas o hayan sido utilizadas para la manipulación de recursos para la fabricación de un enmangue vegetal.

Finalmente, las piezas Z1 14, Z4 54 y Z1 25 (Figura 4 G, I y J) brindaron muestras de grasas que evidencian que las mismas estuvieron en contacto con recursos orgánicos. En el caso de las dos primeras, dado que los ácidos grasos no identificados superan el $20 \%$ no es posible realizar inferencias confiables sobre su origen (Mazzia 2010-2011). Al no presentar tampoco rastros de uso determinables, sólo podemos destacar la posibilidad de conocer que las mismas fueron utilizadas en el pasado sobre recursos orgánicos.

\section{Discusión}

El análisis de sustancias grasas brindó muestras para las 13 piezas arqueológicas, cualquiera sea su tamaño y textura petrográfica, indicando que las mismas estuvieron en contacto prolongado con recursos orgánicos. Por su parte, el análisis funcional permitió determinar con diferentes grados de exactitud el uso de cinco artefactos y la cinemática del trabajo realizado en seis filos, con una alta presencia de rastros no determinables.

En algunos casos, los resultados aportados desde ambas metodologías resultaron complementarse sustentando las observaciones de cada una, como en los casos de Z4 57 y Z1 60 con micropulidos de uso sobre material vegetal duro y madera respectivamente, apoyando la presencia de ácidos grasos de origen vegetal que aparecen mezclados con otros de origen animal. Es similar la situación de los resultados de Z1 59 con claros micropulidos de trabajo de piel, que dan mayor fuerza a la posibilidad de la presencia de ácidos grasos presentes en la piel de guanaco. En estas mismas piezas y en otras (Z4 40, Z1 50 y Z1 34), se destaca la información de las sustancias grasas que indican el procesamiento de recursos animales como carne y peces que generalmente no dejan rastros microscópicos o son fácilmente obliterados por usos posteriores (Kononenko 2011; Leipus 2006; Pal 2012). La ausencia de rastros de uso o su carácter de probables o no determinables 


\begin{tabular}{|c|c|c|c|c|}
\hline \multirow[t]{2}{*}{ Muestra } & \multicolumn{3}{|l|}{ ANÁLISIS CROM ATOGRÁFICO } & \multirow{2}{*}{$\begin{array}{l}\text { ANÁLISIS } \\
\text { FUNCIONAL }\end{array}$} \\
\hline & AG identificados & $\begin{array}{l}\% \text { AG no } \\
\text { identi- } \\
\text { ficados* }\end{array}$ & Interpretación & \\
\hline $\begin{array}{l}\text { Z } \\
\text { Sedimento }\end{array}$ & C14 (2,87); C16 $(16,71) ;$ C18:2 (48,83); C18:3n6 $(1,21)$ & - & $\begin{array}{l}\text { Ausencia de } \\
\text { contaminación de los } \\
\text { objetos }\end{array}$ & - \\
\hline $\begin{array}{l}\text { Z4 } 57 \\
\text { Raedera } \\
\text { OGSB }\end{array}$ & 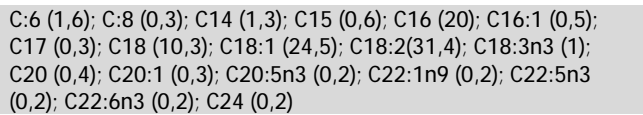 & 6,5 & $\begin{array}{l}\text { Mezcla de recursos } \\
\text { orgánicos }\end{array}$ & $\begin{array}{l}\text { TL/MVD + } \\
T / M V D\end{array}$ \\
\hline $\begin{array}{l}\text { Z1 } 59 \\
\text { FNd } \\
\text { OGSB }\end{array}$ & 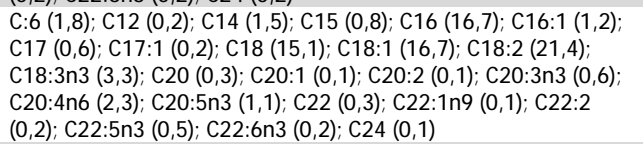 & 14,6 & $\begin{array}{l}\text { Mezcla de recursos } \\
\text { orgánicos. }\end{array}$ & $\Pi / P I$ \\
\hline $\begin{array}{l}\text { Z1 } 60 \\
\text { Instrumento } \\
\text { compuesto } \\
\text { Roca silícea }\end{array}$ & 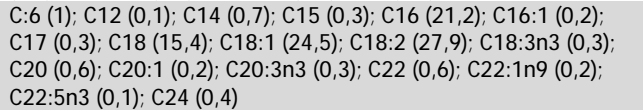 & 5,6 & $\begin{array}{l}\text { Mezcla de recursos } \\
\text { orgánicos }\end{array}$ & $\begin{array}{l}\text { TL/M + } \\
T / M\end{array}$ \\
\hline $\begin{array}{l}\text { Z1 } 34 \\
\text { Lasca } \\
\text { OFB }\end{array}$ & $\begin{array}{l}\text { C:6 (1,41); C12 }(0,69) ; C 14(2,54) ; C 15(0,93) ; C 16(18,09) ; C 16: 1 \\
(0,61) ; C 17(0,39) ; C 18(8,9) ; C 18: 1(19,52) ; C 18: 2(31,94) ; \\
\text { C18:3n3 (1,44);C20 }(0,6) ; C 20: 1(0,21) ; C 20: 4 n 6(0,14) ; C 20: 5 n 3 \\
(0,18) ; C 22(0,24) ; C 22: 1 n 9(0,26) ; C 22: 5 n 3(0,24) ; C 22: 6 n 3 \\
(0,17) ; C 24(0,15)\end{array}$ & 11,36 & $\begin{array}{l}\text { Animales de agua } \\
\text { dulce + vegetales }\end{array}$ & Tा/MI \\
\hline $\begin{array}{l}\text { Z1 } 58 \\
\text { Afs } \\
\text { OGSB }\end{array}$ & $\begin{array}{l}\mathrm{C}: 6(0,95) ; \mathrm{C} 12(0,12) ; \mathrm{C} 14(1,18) ; \mathrm{C} 15(0,55) ; \mathrm{C} 16(21,08) ; \mathrm{C} 17 \\
(0,27) ; \mathrm{C} 18(10,06) ; \mathrm{C} 18: 1(21,48) ; \mathrm{C} 18: 2(35,53) ; \mathrm{C} 18: 3 \mathrm{n} 3(0,9) ; \\
\mathrm{C} 20(0,36) ; \mathrm{C} 20: 1(0,21) ; \mathrm{C} 20: 3 n 3(0,21) ; \mathrm{C} 20: 5 \mathrm{n} 3(0,11) ; \mathrm{C} 22 \\
(0,22) ; \mathrm{C} 22: 1 \mathrm{n} 9(0,11) ; \mathrm{C} 22: 5 \mathrm{n} 3(0,26)\end{array}$ & 6,39 & $\begin{array}{l}\text { Recurso orgánico } \\
\text { indet. }\end{array}$ & Uso probable \\
\hline $\begin{array}{l}\text { Z1 } 13 \\
\text { Lasca bipolar } \\
\text { OGSB }\end{array}$ & 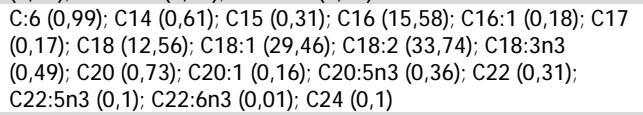 & 4,08 & $\begin{array}{l}\text { Recurso orgánico } \\
\text { indet. }\end{array}$ & $\begin{array}{l}\text { No } \\
\text { determinable }\end{array}$ \\
\hline $\begin{array}{l}\text { Z4 } 3 \\
\text { Lasca angular } \\
\text { OGSB }\end{array}$ & $\begin{array}{l}\text { C:6 (11,45); C8 (1,47); C10 (1,48); C11 (1,39); C12 }(0,94) ; \text { C14 } \\
(9,67) ; \text { C14:1 (2,09); C15 (1,18); C16 (14,9); C18 }(9,03) ; \text { C18:1 } \\
(8,91) ; \text { C18:2 (13,6); C18:3n3 (1,36); C20:3n3 }(2,35) ; \text { C20:5n3 } \\
(1,77) ; \text { C22:5n3 (2,55); C22:6n3 (1,03) }\end{array}$ & 14,82 & $\begin{array}{l}\text { Recurso orgánico } \\
\text { indet. }\end{array}$ & $\begin{array}{l}\text { No } \\
\text { determinable }\end{array}$ \\
\hline $\begin{array}{l}\text { Z1 } 24 \\
\text { Lasca angular } \\
\text { OGSB }\end{array}$ & $\begin{array}{l}\text { C:6 }(3,45) ; C 14(0,47) ; C 15(0,21) ; C 16(16,57) ; C 16: 1(0,18) ; C 17 \\
(0,11) ; \text { C18 }(5,35) ; C 18: 1(23,84) ; C 18: 2(45) ; C 18: 3 n 3(1,11) ; \\
\text { C18:3n6 }(0,9) ; C 20: 1(0,15) ; \text { C20:3n3 }(0,16) ; C 20: 5 n 3 ;(0,11) ; \\
\text { C22:6n3 }(0,21)\end{array}$ & 2,99 & Vegetales & $\begin{array}{l}\text { No } \\
\text { determinable }\end{array}$ \\
\hline $\begin{array}{l}\text { Z4 } 40 \\
\text { Lasca angular } \\
\text { OFB }\end{array}$ & 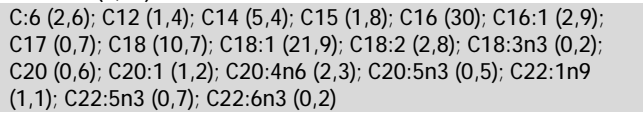 & 11,8 & $\begin{array}{l}\text { Animales terrestres + } \\
\text { posible mástic } \\
\text { vegetal y madera }\end{array}$ & $\begin{array}{l}\text { No } \\
\text { determinable }\end{array}$ \\
\hline $\begin{array}{l}\text { Z1 } 50 \\
\text { Lasca } \\
\text { M etacuarci-ta }\end{array}$ & $\begin{array}{l}\text { C:6 }(2,03) ; C 12(0,53) ; C 14(0,38) ; C 15(1,57) ; C 16(34,22) ; C 17 \\
(0,94) ; C 18(16,29) ; C 18: 1(14,21) ; C 18: 2(9,25) ; C 18: 3 n 3(0,9) ; \\
\text { C20 (0,47); C20:3n3 }(1,02) ; C 20: 5 n 3(0,56) ; C 22: 2(0,9)\end{array}$ & 13,39 & $\begin{array}{l}\text { Animales terrestres + } \\
\text { posible mástic } \\
\text { vegetal y madera }\end{array}$ & $\begin{array}{l}\text { No } \\
\text { determinable }\end{array}$ \\
\hline $\begin{array}{l}\text { Z1 } 14 \\
\text { Lasca de } \\
\text { arista } \\
\text { Cuarzo }\end{array}$ & $\begin{array}{l}\text { C:6 }(10,06) ; C 8(0,48) ; C 10(0,32) ; C 14(2,55) ; C 14: 1(3,08) ; C 15 \\
(4,14) ; C 15: 1(4,35) ; C 16(14,79) ; C 16: 1(0,59) ; C 17(0,6) ; C 18 \\
(8,46) ; C 18: 1(9,1) ; C 18: 2(8,75) ; C 18: 3 n 3(1,17) ; C 20(0,32) ; \\
\text { C20:5n3 }(0,37) ; C 22: 5 n 3(0,56) ; C 22: 6 n 3(0,47)\end{array}$ & 29,85 & - & $\begin{array}{l}\text { No } \\
\text { determinable }\end{array}$ \\
\hline $\begin{array}{l}\text { Z4 } 54 \\
\text { Afs } \\
\text { Indet. }\end{array}$ & $\begin{array}{l}\text { C:6 (6,44); C8 }(0,73) ; \mathrm{C} 10(0,89) ; \mathrm{C} 11(0,64) ; \mathrm{C} 12(0,72) ; \mathrm{C} 13 \\
(0,5) ; \mathrm{C} 14(2,7) ; \mathrm{C} 15(1,02) ; \mathrm{C} 16(17,55) ; \mathrm{C} 16: 1(1,21) ; \mathrm{C} 17 \\
(0,47) ; \mathrm{C} 18(7,40) ; \mathrm{C} 18: 1(6,19) ; \mathrm{C} 18: 2(7,57) ; \mathrm{C} 18: 3 \mathrm{n} 3(2,37) ; \\
\text { C20 (0,31); C20:1 }(0,18) ; \mathrm{C} 20: 3 \mathrm{n} 3(1,52) ; \mathrm{C} 20: 5 \mathrm{n} 3(2,04) ; \\
\text { C22:5n3 }(2,34) ; \mathrm{C} 22: 6 \mathrm{n} 3(1,26)\end{array}$ & 35,96 & - & $\begin{array}{l}\text { No } \\
\text { determinable }\end{array}$ \\
\hline $\begin{array}{l}\text { Z1 } 25 \\
\text { Lasca angular } \\
\text { OFB }\end{array}$ & 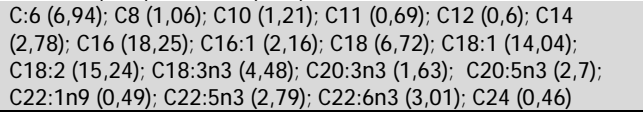 & 14,75 & $\begin{array}{l}\text { Recurso } \\
\text { indet. }\end{array}$ & $\begin{array}{l}\text { No } \\
\text { determinable }\end{array}$ \\
\hline
\end{tabular}

*Entre paréntesis se expresan los porcentajes de cada ácido graso identificado en relación con el total de la muestra. Referencias: FNd: Fragmento no diferenciado de artefacto formatizado; Afs: Artefacto de formatización sumaria; OGSB: ortocuarcita Grupo Sierras Bayas; OFB: ortocuarcita Formación Balcarce; TL: trabajo longitudinal; Tा: trabajo transversal; M: madera; PI: piel; MVD: material vegetal duro; MI: material indeterminado.

Tabla 2. Resultados del análisis funcional y de ácidos grasos sobre las muestras arqueológicas del sitio Cueva Zoro.

Table 2. Results from use-wear and fatty acids analyses of archaelogical samples from Cueva Zoro site. junto con sustancias grasas del procesamiento de carne y vegetales blandos se ve apoyada también por los resultados de los análisis de las piezas experimentales (Tabla 1). Finalmente, un grupo importante de artefactos no tienen rastros de uso determinables y las sustancias grasas registradas se presentan como recursos orgánicos indeterminados. En esos casos sólo puede interpretarse que las piezas fueron utilizadas para procesar algún material orgánico.

Como mencionamos la presencia de rastros de uso diagnósticos requiere diversas condiciones que escapan de nuestros controles y algo similar ocurre con la preservación de sustancias grasas. Además, existen ciertas limitaciones metodológicas en el estudio presentado, ya que al sumergir la pieza completa para la extracción de sustancias grasas es muy difícil realizar una asociación inequívoca entre el micropulido y el recurso orgánico identificado. Para hacer frente a esta limitación, recientemente se puso en práctica una metodología de extracción y análisis (mediante DESI/ MS) que permite obtener muestras de grasa de sectores muy pequeños de los filos (Mazzia et al. 2015), a partir de la cual el posterior análisis microscópico de dichos sectores específicos permitirá obtener resultados más exactos. También resulta indispensable contar con una base de datos de referencia de la composición de ácidos grasos de los diferentes recursos disponibles localmente junto con el registro de los posibles procesos de degradación a los que se vean expuestos (Frère et al. 2010). Igual de imprescindible es el afianzamiento del trabajo interdisciplinario que permita lograr interpretaciones más certeras y ajustar la metodología de análisis de acuerdo con los materiales bajo estudio.

Si bien el análisis cromatográfico ya había sido aplicado en contextos del NOA sobre artefactos líticos tallados (Babot 
et al. 2013, Escola et al. 2013), en esta investigación se han incluido objetos con apenas $2 \mathrm{~cm}$ en su largo máximo. Es destacable, además, el registro del procesamiento de animales de agua dulce y el uso para esa tarea de una lasca de OFB de calidad regular para la talla en la que se identificó una cinemática transversal.

Finalmente, las observaciones experimentales resultaron interesantes para reflexionar sobre cuestiones metodológicas e interpretativas. Por un lado, las sustancias grasas son acumuladas tanto en los filos como en las superficies de los objetos durante sus diferentes usos. Por ello, estas no necesariamente reflejan el último uso de la pieza sino el registro de los diferentes recursos orgánicos con los que estuvo en contacto. Por otro lado, la alta proporción de ácidos grasos no identificados y la notoria proporción de ácidos grasos de cadena media que fueron registradas en el extracto de Eg2 llaman la atención sobre la necesidad de realizar mayores ajustes al momento de interpretar las muestras arqueológicas. Un camino hacia ello podría encontrarse en la ampliación de la muestra experimental como base de datos de referencia.

\section{Conclusión}

Queremos destacar que la combinación de los dos tipos de análisis permitió obtener información sobre el aprovechamiento de recursos orgánicos en un sitio y en una microrregión con escasa preservación de macrorestos vegetales y animales. Esta ausencia de registro de materiales orgánicos macroscópicos puede ser explicada como resultado de un proceso pedogenético que se desarrolla en condiciones muy variables del régimen de humedad, sujeto a fluctuaciones periódicas del nivel freático que generan un ambiente con un potencial muy reducido de preservación de evidencias arqueológicas orgánicas (Zárate 1986/1987). En este contexto, resulta fundamental la aplicación de metodológicas tendientes a recuperar la mayor información posible a partir de los artefactos líticos, el principal registro arqueológico disponible de las actividades pasadas. Dado que se trata de objetos que fueron utilizados hace al menos 10.000 años, esta buena preservación de las sustancias resulta aún más destacable.

Las metodologías integradas en este trabajo brindaron resultados que se complementan y que, incluso en algunos de los casos, otorgan mayor fuerza a las interpretaciones. La aplicación combinada del análisis de sustancias grasas mediante cromatografía gaseosa y del análisis funcional de base microscópica resulta enriquecedora para una comprensión más ajustada del uso de los instrumentos líticos, de los recursos aprovechados, de los trabajos realizados $y$, con ella, un acercamiento a diferentes prácticas cotidianas de los cazadores recolectores pampeanos.

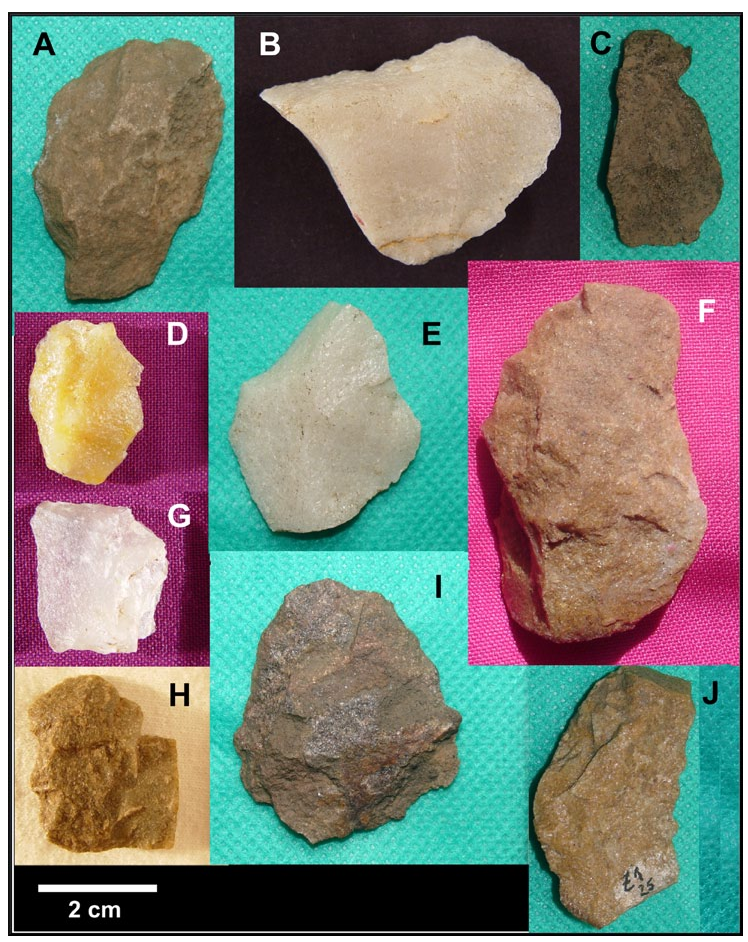

Figura 4. Artefactos de Cueva Zoro seleccionados para análisis. A: Z1 34; B: Z1 58; C: Z1 24; D: Z1 13; E: Z4 3; F: Z4 40; G: Z1 14; H: Z1 50; I: Z4 54; J: Z1 25.

Figure 4. Selected tools from Cueva Zoro. A: Z1 34; B: Z1 58; C: Z1 24; D: Z1 13; E: Z4 3; F: Z4 40; G: Z1 14; H: Z1 50; I: Z4 54; J: Z1 25.

\section{Agradecimientos}

Este trabajo fue posible gracias a la invalorable ayuda de muchas personas en sus diferentes etapas. La hospitalidad de la familia Rocattagliatta Pérez y la buena predisposición del Sr. Petrozzi hicieron que todo sea más fácil en el campo. En el análisis microscópico colaboraron pacientemente Marilina Martucci, Marcelo Cardillo y Nora Franco. Los análisis de ácidos grasos recibieron el impulso inicial de María del Pilar Babot, Magdalena Frère, e Isabel González y la paciencia en el laboratorio de Diana Constela y Marcela Sánchez, además de la gran generosidad de la empresa Materia Hnos. Por último, Leonardo Mazzia clarificó muchas de nuestras dudas y Nora Flegenheimer nos apoyó en cada paso. A los dos evaluadores anónimos de este trabajo, cuyas observaciones contribuyeron a la mejora del mismo. Este trabajo fue financiado por los subsidios PICT 2014-3054, PIP 112 -201101-00177, PICT Bicentenario 2010-2648 y PIP 0452 2011-2013.

\section{Bibliografía}

Abd El-Baky, H., F.K. El Baz y G.S. El-Baroty. 2004. Production of lipids rich in Omega3 fatty acids from the halo tolerant alga Dunaliella salina. Biotechnology 3 (1): 102-108.

Anónimo, 1993. A\&G Técnica. №10.

Álvarez, M. 2000-2002. El trabajo del hueso en la costa norte del canal Beagle: técnicas de manufactura a través del análisis funcional de instrumentos líticos. Cuadernos del INAPL 19: 49-70.

Álvarez, M., D. Zurro, I. Briz, M. Madella, M. Osterrieth y N. Borelli. 2009. Análisis de los procesos productivos de las 
sociedades cazadoras-recolectoras-pescadoras de la costa norte del canal Beagle (Argentina): el sitio Lanashuaia. M. Salemne, F. Santiago, M. Álvarez, E. Piana, M. Vázquez, M.E. Mansur, Arqueología de la Patagonia. Una mirada desde el último confín, pp. 903-917. Editorial Utopías, Ushuaia.

Anderson, P. C. 1980. A testimony of prehistoric tasks: diagnostic residues on stone tool working edges. World Archaeology 12: 181-194.

Anderson-Gerfaud, P. 1981. "Contribution methodologique a I'analyse des microtraces d'utilisation sur les outils prehistoriques". Géologie du Quaternaire et Préhistoire, Universidad de Bordeaux I, Francia, p: 314.Tesis de Doctorado.

Babot, M. P. 2004. "Tecnología y utilización de artefactos de molienda en el Noroeste Prehispánico". Facultad de Ciencias Naturales e IML, Universidad Nacional de Tucumán, Argentina, p: 303.Tesis de Doctorado.

Babot, M. P, N. Mazzia y C. Bayón 2007. Procesamiento de recursos en la región pampeana bonaerense: aportes del instrumental de molienda de las localidades arqueológicas El Guanaco y Cerro La China. C. Bayón, N. Flegenheimer, M. I. González, M. Frère y A. Pupio, Arqueología en las pampas, Tomo II, pp. 635-660. SAA, Buenos Aires.

Babot, M. P, S. Hocsman y R. Cattáneo. 2013. Assessing the life history of projectile points/knives from the Middle Holocene of Argentina's Southern Puna. Quaternary International 287: 3-19.

Barton, H., R. Torrence y R. Fullagar. 1998. Clues to Stone Tool Function Re-examined: Comparing Starch Grain Frequencies on Used and Unused Obsidian Artefacts. Journal of Archaeological Science 25(12): 1231-1238.

Bayón, C, N. Flegenheimer y A. Pupio. 2006. Planes sociales en el abastecimiento y traslado de rocas en la Pampa bonaerense en el Holoceno Temprano y Tardío. Relaciones de la Sociedad Argentina de Antropología 31: 19-27.

Bondia Pons, I. 2007. Estudio del perfil de ácidos grasos en la evaluación de la dieta mediterránea como patrón de dieta saludable en poblaciones europeas. Facultad de Farmacia, Universidad de Barcelona, España. Tesis de Doctorado.

Bonomo, M., M. Colobig y N. Mazzia. 2012. Análisis de residuos orgánicos y mi-crofósiles silíceos de la "cuchara" de cerámica del sitio arqueológico Cerro Tapera Vázquez (Parque Nacional Pre-Delta, Argentina). Revista do Museu de Arqueologia e Etnologia 22: 31-50.

Borel, A., A. Ollé, J. M. Vergès y R. Sala. 2014. Scanning Electron and Optical Light Microscopy: two complementary approaches for the understanding and interpretation of usewear and residues on stone tools. Journal of Archaeological Science 48: 46-59.

Brenner, R. R. y A. M. Bernasconi.1997. Aporte de ácidos grasos esenciales de las series n-6 y n-3 a la dieta humana por pescados comestibles del Río Paraná. Medicina 57: 307- 314.

Briz Godino, I., D. Zurro, M. Álvarez y M. Madella. 2014. Ethnoarchaeology and Residue Analysis in Fisher-HunterGatherer Sites. M. Roksandic, S. Mendoça de Souza, S. Eggers, M. Burchell, D. Kloker, The Cultural Dynamics of Shell Middens and Shell Mounds: A worldwide perspective, pp: 267-277. New México University Press, Albuquerque.

Buonasera, T. 2007. Investigating the presence of ancient absorbed organic residues in groundstone using GCeMS and other analytical techniques: A residue study of several prehistoric milling tools from central California. Journal of Archaeological Science 34: 1379-1390.

Cañabate Guerrero, M. L. y A. Sánchez Vizcaíno. 1995. Análisis de indicadores bioquímicos del contenido de recipientes arqueológicos. Complutum 6: 281- 291.

Castro de Aguilar, A. 1994. “Estudios de Análisis Funcional de material lítico: Un modelo alternativo de clasificación tipológica". Facultad de Ciencias Naturales y Museo, Universidad Nacional de La Plata. Tesis de Doctorado.

Cesaro, S. N., y C. Lemorini. 2012. The function of prehistoric lithic tools: A combined study of use-wear analysis and FTIR microspectroscopy. Spectrochimica Acta 86(A): 299-304.

Cooper, J. y Nugent, S. 2009. Tools on the surface: residue and use-wear analyses of stone artefacts from Camooweal, northwest Queensland. M. Haslam, G. Robertson, A. Crowther, S. Nugent y L. Kirkwood, Archaeological Science Under a Microscope: Studies in Residue and Ancient DNA Analysis in Honour of Thomas H. Loy, pp. 207-227. ANU E Press, Canberra.

Cordero, J. A. y R. March. 2013. Análisis de ácidos grasos en fragmentos cerámicos del noroeste de la Patagonia Argentina por GC y GC-MS. M. S. Ramos, M. Lanza, V. Helfer, V. Pernicone, F. Bognanini, C. Landa, V. Aldazabal y M. Fernández, Arqueometría argentina. Estudios pluridisciplinarios, pp.195220. Universidad Nacional de Luján.

Costa Angrizani, R. y D. Constenla. 2010. Sobre yapepós, ñaembés y cambuchís: aproximaciones a la funcionalidad de vasijas cerámicas a partir de la determinación de ácidos grasos residuales en tiestos recuperados en contextos arqueológicos en el sur de Brasil. M. Berón, L. Luna, M. Bonomo, C. Montalvo, C. Aranda y M. Carrera Aizpitarte, Mamül Mapu: pasado y presente desde la arqueología pampeana, pp5-52. Editorial Libros del Espinillo, Buenos Aires.

Di Prado, V., R. Scalise, D. G. Poiré, J. M. Canalicchioy L. Gómez Peral. 2007. Análisis de elementos colorantes provenientes del sitio Calera (Sierras Bayas, región pampeana). Una exploración del uso social y ritual de los pigmentos. C. Bayón, N. Flegenheimer, M. I. González, M. Frère y A. Pupio, Arqueología en las pampas, Tomo II, pp.765-780. SAA, Buenos Aires.

Eerkens, J. W. 2007. Organic residue analysis and the decomposition of fatty acids in ancient potsherds. H. Barnard y J.W. Eerkens, Theory and Practice in Archaeological residue analysis, pp. 90-98. BAR, Int. Series, Archaeopress, Oxford.

Escola, P., S. Hocsman y M. P. Babot. 2013. Entre las residencias y los campos de cultivo. Aportes de los cuchillos/raederas de módulo grandísimo a la cuestión del laboreo agrícola en Antofagasta de la Sierra (Puna de Catamarca) durante el primer milenio d.C. Relaciones de la Sociedad Argentina de Antropología 38: 83-110.

Evershed, R. P. 1993. Biomolecular archaeology and lipids. World Archaeology 25: 74-93. 
Evershed, R. P. 2008. Experimental approaches to the interpretation of absorbed organic residues in archaeological ceramics. World Archaeology 40: 26-47.

Evershed, R. P., C. Heron, S. Charters y L. J. Goad. 1992. Chemical analysis of organic residues in ancient pottery: methodological guidelines and applications. R. White y H. Page, Organic residues in archaeology: their identification and analysis, 11-25. UKIC Archaeology Section, London.

Evershed R. P., S. N. Dudd, M. S. Copley, R. Berstan, A. W. Stott, H. Mottram, S. A. Buckley y Z. Crossman. 2002. Chemistry of archaeological animal fats. Accounts of Chemical Research 35(8): 660-668.

Fankhauser, B. 1994. Protein and lipid analysis of food residues. J. G. Hather, Tropical Archaeobotany: Applications and New Development, pp. 227-250. Routledge.

Feiser, L. F. y M. Feiser. 1960. Química orgánica. Grijalbo, México.

Fezler, D. 1995. Rhea oil. Claire Drenowatz, The Ratite Encyclopedia. Ostrich, Emu, Rhea, 245- 250. Ratite Recods, Texas.

Fiore, D., M. Maier, S. D. Parera, L. Orquera y E. Piana. 2008. Chemical analyses of the earliest pigment residues from the uttermost part of the planet (Beagle Channel region, Tierra del Fuego, Southern South America). Journal of Archaeological Science 35: 3047-3056.

Flegenheimer, N. 2003. Cerro El Sombrero, a locality with a view. L. Miotti, M. Salemme y N. Flegenheimer, Where the South Winds Blow, Ancient Evidence of Paleo South Americans, pp. 51-56. CSFA-A\&M University Press, Texas.

Flegenheimer, N. 2004. Las Ocupaciones de la transición Pleistoceno-Holoceno: una visión sobre las investigaciones en los últimos 20 años en la Región pampeana. L. Beovide, I. Barreto y C. Cubelo, La arqueología uruguaya ante los desafíos del nuevo siglo. $C D$.

Flegenheimer, N. y C. Bayón. 2000. New Evidence for Early Occupations in the Argentine Pampas, Los Helechos Site. Current Research in the Pleistocene 17: 24-26.

Flegenheimer, N y M. Leipus. 2007. Trabajar en un espacio reducido, Cerro El Sombrero, Abrigo 1. XVI Congreso Nacional de Arqueología Argentina Tomo I: 441-444, Jujuy.

Flegenheimer, N., N. Mazzia y M. Babot. 2013. Estudios de detalle sobre una piedra discoidal pampeana. Intersecciones en Antropología 14: 499-505.

Flegenheimer, N., C. Weitzel y N. Mazzia. 2015. Miniature points in an exceptional early South American context. World Archaeology 47(1): 117-136.

Frère, M. M., D. Constenla, C. Bayón y M. I. González 2010. Estudios actualísticos sobre recursos silvestres mediante el empleo de análisis químicos. M. Berón, L. Luna, M. Bonomo, C. Montalvo, C. Aranda y M. Carrera Aizpitarte, MamülMapu: pasado y presente desde la arqueología pampeana, pp. 215226. Editorial Libros del Espinillo, Buenos Aires.
Fullagar, R., L. Liu, S. Bestel, D. Jones, W. Ge, A. Wilson y S. Zhai. 2012. Stone tool-use experiments to determine the function of grinding stones and denticulate sickles. Bulletin of the IndoPacific Prehistory Association 32: 29-44.

Fullagar, R., E. Hayes, B. Stephenson, J. Field, C. Matheson, N. Stern y K. Fitzsimmons. 2015. Evidence for Pleistocene seed grinding at Lake Mungo, south-eastern Australia. Archaeology in Oceania 50: 3-19.

Galanidou, N. 2006. Analytical and Ethical Issues Concerning Organic Residues on Paleolithic Chipped Stone Tools from NW Greece. Journal of Field Archaeology 31: 351-362.

Gibaja, J. F., I. Clemente-Conte y A. Mir. 2002. Análisis funcional en instrumentos de cuarcita: el yacimiento del paleolítico superior de la Cueva de la Fuente del Trucho (Colungo, Huesca). I. Clemente-Conte, R. Risch y J. F. Gibaja, Análisis Funcional: su aplicación al estudio de sociedades prehistóricas, pp. 79-86. Archaeopress, Oxford.

Gómez Otero, J., D. Constenla y V. Schuster. 2014. Análisis de isótopos estables de carbono y nitrógeno y cromatografía gaseosa en cerámica arqueológica del nordeste de la provincia de Chubut (Patagonia Argentina). Arqueología 20(2): 263-284.

González de Bonaveri, M.I. y M. Frère. 2002. Explorando algunos usos prehispánicos de la alfarería pampeana. Mazzanti, D., M. Berón, F. Oliva, Del Mar a los Salitrales. Diez Mil Años de Historia Pampeana en el Umbral del Tercer Milenio, pp. 31-40. Universidad Nacional de Mar del Plata, Buenos Aires.

González De Bonaveri, M.I. y M. Frère. 2004. Analysis of potsherd residues and vessel use in hunter-gatherer-fisher groups (Pampean Region, Argentina). Secrétariat du Congrès, Actas del XIV UISPP Congress, pp. 27-35. BAR Series 1270, Oxford.

Gunstone, F.D., J. L. Harwood y A. J. Dijkstra. 2007. The Lipid Handbook. CRC Press, Boca Raton.

Hardy, B. L. 2009. Understanding Stone Tool Function: Methods and Examples from the Aurignacian Levels at Hohle Fels. Mitteilungen der Gesellschaftfür Urgeschichte 18: 109-121.

Hardy B. L. y G. T. Garufi. 1998. Identification of Woodworking on Stone Tools through Residue and Use-Wear Analyses: Experimental Results. Jounal of archaeological Science 25(2): 177-184.

Hardy, B.L. y M. H. Moncel. 2011. Neanderthal Use of Fish, Mammals, Birds, Starchy Plants and Wood 125-250,000 Years Ago. PLOS ONE 6(8): e23768.

Hardy, B. L., M. Kay, A. E. Mark, y K. Monigal. 2001. Stone tool function at the paleolithic sites of Starosele and Buran Kaya III, Crimea: Behavioral implications. PNAS 98(19): 10972-10977.

Högberg, A., K. Puseman y C. Yost. 2009. Integration of usewear with protein residue analysis. A study of tool use and function in the south Scandinavian Early Neolithic. Journal of Archaeological Science 36: 1725-1737.

Hurcombe, L. M. 1992. Use-wear analysis and obsidian: theory experiments and results. Sheffield Archaeological Monographs 4, Sheffield. 
Illescas, F., A. Cañizo, M. G. Musaubach y M. A. Berón. 2012. De ollas, aceites y otras yerbas. Análisis complementarios sobre alfarería pampeana. M. P. Babot, M. Marschoff y F. Pazzarelli, Las manos en la masa. Arqueologías, Antropologías e Historias de la Alimentación en Suramérica, pp. 387-404. Museo de Antropología, Córdoba.

IUPAC, 1997. Compendium of Chemical Terminology, Compilado por McNaught, A.D., Wilkinson, A. Blackwell, Blackwell, Oxford.

Kealhofer, L., R. Torrencey R. Fullagar. 1999. Integrating Phytoliths within Use-Wear/Residue Studies of Stone Tools. Journal of archaeological Science 26(5): 527-546.

Keeley, L. H. 1980 Experimental Determination of Stone Tool Uses: A Microwear Analysis. The University of Chicago Press, Chicago.

Kononenko, N. 2007. The contribution of use-wear/residue studies of obsidian artefacts for understanding changes in settlement and subsistence patterns in west New Britain, Papua New Guinea. Bulletin of the Indo-pacific Prehistory Association 27: $135-143$.

Kononenko, N. 2011. Experimental and archaeological studies of use-wear and residues on obsidian artefacts from Papua New Guinea. Technical Reports of the Australian Museum, Online 21: 1-244.

Langejans, G.H.J. y M. Lombard. 2015. About small things and bigger pictures: An introduction to the morphological identification of micro-residues on stone tools. J. Marreiros, M. Gibaja Bao, J. F. Ferreira y N. Bicho, Use-Wear and Residue Analysis in Archaeology, pp. 199-219. Springer, Heidelberg.

Leipus, M. 2006. “Análisis de los modos de uso prehispánicos de las materias primas líticas en el Sudeste de la Región Pampeana: Una aproximación funcional". Facultad de Ciencias Naturales y Museo, Universidad Nacional de La Plata, Argentina, p: 383. Tesis de Doctorado. FCNyM, La Plata.

Leipus, M. 2010. El uso de los conjuntos líticos tempranos de Tandilia (Región Pampeana, Argentina): evidencias a partir del análisis funcional de base microscópica. Abstracts of the $\mathrm{Vth}$. International Symposium "Early Man in America", pp. 80-81. La Plata, Argentina.

Leipus, M. y M. E. Mansur. 2007. El análisis funcional de base microscópica aplicado a materiales heterogéneos. Perspectivas metodológicas para el estudio de las cuarcitas de la región pampeana. C. Bayón, N. Flegenheimer, M. I. González, M. Frère y A. Pupio Arqueología en las pampas, tomo I, pp. 179-200. SAA, Buenos Aires.

Liu, L., J. Field, R. Fullagar, S. Bestel, X. Chen y X. Ma. 2010. What did grinding stones grind? New light on early Neolithic subsistence economy in the Middle Yellow River Valley, China. Antiquity 84(325): 816-833.

Lombard, M. 2005. Evidence of hunting and hafting during the Middle Stone Age at Sibidu Cave, KwaZulu-Natal, South Africa: a multianalytical approach. Journal of Human Evolution 48: 279-300. Doi: 10.1016/j.jhevol.2004.11.0006.

Lombard, M. y L. Phillipson. 2010. Indications of bow and stone-tipped arrow use 64000 years ago in KwaZulu-Natal,
South Africa. Antiquity 84: 635-648.

Maier, M. S., D. L. A. De Faria, M. T. Boschín, S. D. Pareray M. F. Del Castillo Bernal 2007. Combined use of vibrational spectroscopy and GC-MS methods in the characterization of archaeological pastes from Patagonia. Vibrational Spectroscopy 44: 182-186.

Malainey, M. E., R. Przybylski y B. L. Sherriff. 1999. The Fatty Acid Composition of Native Food Plants and Animals of Western Canada. Journal of Archaeological Science 26: 83- 94.

Malainey, M. E. 2007. Fatty Acid Analysis of Archaeological Residues: Procedures and Possibilities. H. Barnard y J. Eerkens, Theory and Practice of Archaeological Residue Analysis, capítulo 7, pp 77-89. BAR International, Oxford.

Mansur-Franchomme, M. E. 1983. "Traces d'utilisation et technologie lithique: exemples de la Patagonie".Géologie du Quaternaire et Préhistoire, Université de Bordeaux, Francia, p: 516. Tesis de Doctorado.

Mansur-Franchomme, M.E. 1986-1990.Instrumentos líticos: Aspectos da analise funcional. Arquivos do Museu de Historia Natural 11: 115-169.

Mansur, M. E. 1999. Análisis funcional de material lítico: problemas de formación y deformación de rastros de uso. Actas del XII Congreso Nacional de Arqueología Argentina (I): 355-366. Editorial de la UNLP, La Plata.

Mansur, M. E. y A. Lasa. 2005. Diversidad artefactual vs especialización funcional. Análisis del IV Componente de Túnel I (Tierra del Fuego, Argentina). Magallania 33(2): 69-91.

Mazzia, N. 2010-2011. "Lugares y paisajes de cazadoresrecolectores en la pampa bonaerense: cambios y continuidades durante el Pleistoceno final-Holoceno". Facultad de Ciencias Naturales y Museo, Universidad Nacional de La Plata, p: 473. Tesis de Doctorado. FCNyM, La Plata.

Mazzia, N. 2011. El Ajarafe: Un espacio serrano ocupado efímeramente en diferentes momentos del Holoceno (Tandilia, Provincia de Buenos Aires). Revista del Museo de Antropología 4: 33-46.

Mazzia, N. 2013. Cueva Zoro: nuevas evidencias sobre pobladores tempranos en el sector centro oriental de Tandilla. Intersecciones en Antropología 14: 93-106. Mazzia, Mazzia, N. 2013b. Lugares y paisajes de cazadores recolectores pampeanos: una propuesta para su estudio. Revista del Museo de La Plata, Sección Antropología 13: 233-253.

Mazzia, N. y N. Flegenheimer 2012. Early Settlers and their Places in the Tandilia Range (Pampean Region, Argentina). L. Miotti, M. Salemme, N. Flegenheimer y T. Goebel, Southbound. Late Pleistocene Peopling of Latin America., pp. 105-10. A\&M University Press, College Station.

Mazzia, N. y N. Flegenheimer. 2015. Detailed fatty acids analysis on lithic tools, Cerro El Sombrero Cima, Argentina. Quaternary International 363: 94-106.

Mazzia, N., J. Brardinelli y D. Roncaglia. 2015. Nueva técnica de análisis de sustancias grasas sobre objetos líticos tallados. Presentado en VI Congreso Nacional de Arqueometría, Río Cuarto. 
Muhamad, N. A. y J. Mohamad. 2012. Fatty acids composition of selected Malaysian fishes. Sains Malaysiana 41(1), 81-94.

Pal, N. 2012. "Tendencias temporales en las estrategias deexplotación y uso de los materiales líticos de la cuencasuperior del arroyo Tapalqué (Partidos de Benito Juárez y Olavarría): Una perspectiva desde el Análisis Funcional". Facultad de Ciencias Sociales, Universidad Nacional del Centro de la Provincia de Buenos Aires, Argentina, pp: 131, Tesis Doctoral. UNICEN.

Patrick, M., A. J. De Koning y A. B. Smith.1985. Gas liquid chromatographic analysis of fatty acids in food residues from ceramics found in the Southwestern cape, South Africa. Archeometry 27(2): 231- 236.

Pawlik, A. 2004.Identification of hafting traces and residues by scanning electron microscopy and energy dispersive analysis of X-rays. E. A. Walker, F. Wenban-Smith, F. y F. Healy, Lithics in Action: Papers from the conference Lithic Studies in the Year 2000, pp. 169-179. Oxbow Books, Oxford.

Pedergnana, A. y R. Blasco. 2015. Characterising the exploitation of avian resources: An experimental combination of lithic use-wear, residue and taphonomic analyses. Quaternary International. En prensa.

Pérez, M., I. Acosta, G. Naranjo y L. Malec. 2013. Uso de la alfarería y conductas alimenticias en el humedal del Paraná inferior a través del análisis de ácidos grasos. Cuadernos del Instituto Nacional de Antropología y Pensamiento Latinoamericano 1(1): 26-45.

Pérez Meroni, M., M. C. Paleo, M. L. Pochettino y V. S. Lema 2010. Procesamiento y consumo de vegetales por grupos cazadores-recolectores del Holoceno tardío, en los partidos de Magdalena y Punta Indio, provincia de Buenos Aires. M. Berón, L. Luna, M. Bonomo, C. Montalvo, C. Aranda y M. Carrera Aizpitarte, Mamül Mapu: pasado y presente desde la arqueología pampeana, pp. 87-102.Editorial Libros del Espinillo, Buenos Aires.

Perry, L. 2002. Starch analyses reveal multiple functions of quartz "manioc" grater flakes from the Orinoco Basin, Venezuela. Interciencia 27(11): 635-639.

Pond, D., D. Dixon, M. Bell, A. Fallicky J. Sargent 1997. Occurrence of 16:2 (n-4) and18:2 (n-4) fatty acids in the lipids of the hydrothermal vent Shrimps Rimicaris Exoculata and Alvinocaris Markensis: Nutritional and Trophic Implications. Marine Ecology Progress Series 156: 167-174.

Portillo, M., M. Bofill, M. Molisty R. M. Albert. 2013. Phytolith and use-wear functional evidence for grinding stones from the Near East. P. C. Anderson, C. Cheval y A. Durand, Regards croisésn sur les outils liés au travail des végétaux, pp. 205-218. APDCA, Antibes.

Regert, M. 2011. Analytical strategies for discriminating archeological fatty substances from animal origin. Mass Spectrom 30: 177-220.

Robertson, G. y V. Attenbrow. 2008. Skin-working at Emu Tracks 2, New South Wales, Australia: an integrated residue and use-wear analysis of backed artefacts. Lithic Technology 33(1): 31-49.
Robertson, G., V. Attenbrow y P. Hiscock. 2009. Multiple uses for Australian backed artefacts. Antiquity 83: 296-308.

Robinson, D., M. Calvo Rebollar y E. Sevillano Calvo. 1991. Bioquímica y valor nutritivo de los alimentos. Ed. ACRIBIA, España.

Rottländer, R. C. A. 1990. Lipid analysis in the identification of Wessel contents. MASCA Research papers in Science and Archaeology 7: 37-40.

Rots, V. 2010.Prehension and hafting traces on Flint Tools: A methodology. Leuven University Press, Bélgica.

Rots, V. 2014. What method to study hafting? The potential of use-wear and residue analysis confronted. C. Lemorini y S. N. Cesaro, An Integration of the Use-Wear and Residue Analysis for the Identification of the Function of Archaeological Stone Tools, pp: 27-41. BAR International Series 2649, Archaeopress, Oxford.

Rots, V. y B. S. Williamson. 2004. Microwear and residue analyses in perspective: the contribution of ethnoarchaeological evidence. Journal of Archeological Science 31: 1287-1299.

Semenov, S. 1964. Prehistoric technology. Adams and Dart, Londres.

Sengör, F., Ö. Özden, N. Erkan, M. Tüter y H. Ayseaksoy. 2003. Fatty acid compositions of flathead grey mullet (Mugilcephalus L., 1758) fillet, raw and bees-waxed caviar oils. Turkish Journal of Fisheries and Aquatic Sciences 3: 93-96.

Sterner Miller, K. M., R. J. Jeske y S. A. Shuler. 2013. Results of Blood Residue Analysis and Microwear of Suspected Arrowpoints and Scraping Tools from The Crescent Bay Hunt Club Site (47je904). Presentado en 2013 Midwest Archaeological Conference, Ohio.

Stoessel, L., Martínez, G. y D. Constenla. 2015. Análisis preliminar de ácidos grasos recuperados de cerámicas arqueológicas del curso inferior del río colorado (norpatagonia oriental): aportes para la subsistencia de grupos cazadoresrecolectores. Magallania 23(1): 231-249.

U. S. Testing Company, INC. S/F. Chemical and Physical Tables. Tables and Data from United States Testing Company, Inc. New Jersey, 28-29.

Valverde, F. 2006. Estrategias de conservación y economía de la materia prima lítica en contextos tempranos de las sierras de Tandilia oriental. Cazadores-recolectores del Cono Sur1: 179-187.

Van Gijn, A. 1986. Fish Polish, Fact and Fiction. Early Man News 11: 13-28.

Vila, A. y F. Gallart. 1993. Caracterización de los micropulidos de uso: ejemplo de aplicación del análisis de imágenes digitalizadas. P.C. Anderson, S. Beyries, M. Otte y H. Plisson, Traces et fonction: les gestes retrouvés 50, vol. 2, 459-466. CRA du CNRS, Liège.

Zárate, M. 1986/1987. Marco estratigráfico y geológico del sitio 3 de la localidad arqueológica Cerro La China (Provincia de Buenos Aires). Relaciones de la Sociedad Argentina de Antropología XVII 1:29-35. 